\title{
Enhanced Desolvation and Improved Deposition Efficiency by Modified Thermospray for the Coupling of HPLC and FT-IR
}

\author{
Mohammad A MotTALEB ${ }^{\dagger}$ and Hyo-Jin KIM \\ Department of Pharmacy, Dongduk Women's University, 23-1 Sungbuk-ku, Seoul 136-714, South Korea
}

\begin{abstract}
A thermospray interface was modified for the on-line coupling of normal- and reversed-phase high-performance liquid chromatography (HPLC) and Fourier transform infrared (FTIR) spectrometry. An LC/FTIR assembly was used to evaporate the column effluents and the solutes were deposited as a series of individual spots on a stainless-steel moving belt, which continuously transferred the solutes into a diffuse reflectance accessory of FTIR, enabling the identification of deposited solutes by measuring the IR spectrum. A lowered desolvation temperature of reversed-phase HPLC eluents, a higher deposition efficiency, such as $69 \%$, and a reduction of the thermospray capillary voltage were achieved by using a heated gas flow and a heating plate. The thermospray temperature and the distance between the tip of the thermospray tubing and the surface of the belt were shown to influence the area of deposition of spots. A variation of $\pm 1^{\circ} \mathrm{C}$ could be used for a sensitive and reproducible deposition of Irganox 565 with a relative standard deviation (RSD) of 1.8 to $2.5 \%$. The UV and FTIR chromatograms gave similar features for the HPLC-separated constituents. The interface-derived IR spectra of the constituents showed excellent agreement of the spectral features with those of the standard FTIR spectra, and no thermal degradation was found to occur.
\end{abstract}

(Received September 10, 2001; Accepted February 7, 2002)

\section{Introduction}

The interface is a critical component and plays a dominant role in combining HPLC and FTIR spectrometry. The success or failure of the technique almost exclusively depends on the interface performance. In general, flow cells ${ }^{1-3}$ and solvent elimination ${ }^{4-18}$ procedures have been used for the interfacing of HPLC to FTIR. Although more convenient, the usefulness of the flow-cell procedure is limited because the aqueous-based mobile phase, commonly used in reversed phase (RP)-HPLC, strongly absorbs IR radiation in many areas of the IR spectrum, resulting in a loss of sample spectral information. More favorable results can be obtained if a solvent-elimination technique is applied prior to FTIR detection.

Wood $^{4}$ demonstrated the suitability of particle-beam HPLCFTIR by depositing column effluents onto a $\mathrm{KBr}$ substrate from a normal-phase (NP)-HPLC solvent. This technique was only open to an NP-HPLC eluent, where non-aqueous mobile phase solvents were used. Fujimoto et al. ${ }^{5}$ employed stainless-steel wire nets (SSWN) in lieu of applying water-soluble metal halide substrates for RP-HPLC. Solvents were evaporated using a heated nitrogen gas flow, and solutes were trapped in the metal nets. Although the major advantage of the procedure was the insolubility of SSWN in the aqueous phase, it was operated at an extremely low flow rate of $4 \mu \mathrm{min}^{-1}$. A narrow-bore RP-

† To whom correspondence should be addressed.

Present address: EPA/NRC Postdoctoral Research Associate, Environmental Sciences Division, National Exposure Research Laboratory, US Environmental Protection Agency, P. O. Box 93478, Las Vegas NV 89193-3478, USA.

E-mail: Mottaleb.Mohammad@epamail.epa.gov
HPLC-FTIR method was developed by Gagel and Biemann. ${ }^{6}$ Effluents were continuously deposited onto and evaporated from the surface of a reflective disk using a nitrogen gas nebulizer. The system offered good sensitivity (31 ng for quinoline) and could be used with up to $50 \%$ water content at a flow rate of $30 \mu \mathrm{min}^{-1}$. A commercial version of this interface, the LC-Transform, was applied to determine polymers ${ }^{7}$ and steroids. ${ }^{8}$ The LC-Transform differs from Gagel and Biemann's system in that the solutes are deposited on the top of a germanium disk with an aluminum coating underneath to increase the absorption by the solutes. However, problems were encountered with both systems when the effluent contained nonvolatile solutes, such as phosphate buffers, which tended to accumulate on the disk.

A nebulizing gas, mono-disperse aerosol generation HPLC to the FTIR interface, was developed by Robertson et al..$^{9,10}$ The system was capable of vaporizing $100 \%$ water at a flow rate of $300 \mu 1 \mathrm{~min}^{-1}$. Although higher concentrations of volatile buffers were used by this interface, only about a $10 \%$ deposition efficiency was reported. This system was employed for determining methyl red ${ }^{9}$ and caffeine ${ }^{10}$ with detection limits of $100 \mathrm{ng}$ and $13 \mu \mathrm{g}$, respectively. Griffiths and co-workers ${ }^{11,12}$ described an HPLC-FTIR interface based on a concentric flow nebulizer, in which the mobile phase was continuously evaporated as the solutes were deposited onto a $\mathrm{ZnSe}$ window. This interface was suitable for NP- and RP-HPLC solvents, including eluents containing low concentrations of volatile buffers.

Jansen $^{13}$ demonstrated a thermospray interface, which was operated with $30 \%$ water at $500 \mu \mathrm{min}^{-1}$. Although detection limits of about $100 \mathrm{ng}$ were achieved, no information was provided on solute spreading and the deposition efficiency. Robertson et al. ${ }^{14}$ described a similar thermospray for HPLC- 
FTIR hyphenation. This interface was used with a $100 \%$ aqueous eluent at $500 \mu \mathrm{l} \mathrm{min}{ }^{-1}$, and a temperature of $280^{\circ} \mathrm{C}$ was reported to desolvate the eluent. At high temperatures, thermal degradation of the solute was also reported. We modified the device by introducing a gas flow system which permitted operation with pure water and at a reasonable flow rate; this was used with RP-HPLC-FTIR to analyze antioxidants and amino acids. ${ }^{15}$ This hyphenated technique was recently employed to analyze linear alkylbenzene sulfonates ${ }^{16}$ and reactive dyes..$^{17,18}$ Although the use of a heated gas flow at a rate of $61 \mathrm{~min}^{-1}$ reduced the thermospray temperature, ${ }^{15}$ deposition problems, thermospray capillary blockage, a loss of resolution in FTIR chromatograms, ${ }^{15-17}$ and peak splitting ${ }^{18}$ were experienced. To keep these problems in mind, we further revised, or developed, glass thermospray by introducing another heated gas flow channel and a heating plate underneath the deposition belt to enhance the eluent evaporation and to improve the resolution in the FTIR detection chromatograms, respectively. This paper reports on an improved HPLC-FTIR thermospray interface with enhanced performance resulting from a lower desolvation temperature and a lower thermospray capillary voltage, as well as improved resolution of peaks owing to the moving stainlesssteel belt.

\section{Experimental}

\section{Chromatography and spectroscopy}

A liquid chromatograph (Samsung, Model SLC 100, Korea) equipped with a Rheodyne Model 7125 syringe loading injector (Berkeley, CA, USA) and a $20 \mu \mathrm{l}$ sample loop was used. A UV/VIS detector (Samsung, Model SLC 200, Korea) was connected to the HPLC instrument. Effluents were passed through a stainless-steel ODS column $(250 \times 4.6 \mathrm{~mm}$ i.d. $)$ and monitored at $275 \mathrm{~nm}$ prior to FTIR detection. Degassed acetonitrile, methanol and water were pumped through the

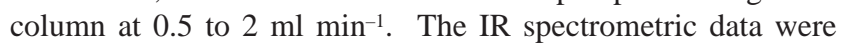
collected by a Philips 9800 series FTIR spectrometer (Cambridge, UK) equipped with a Spectra-Tech diffuse reflectance infrared Fourier transform (DRIFT) accessory (Stanford, CT, USA) as interferrograms at a resolution of 8 or $16 \mathrm{~cm}^{-1}$. The collected IR data were stored in the FTIR computer software. After each analysis, interferrograms were transformed to IR transmission or absorption spectra by using a fast-Fourier-transform algorithm.

\section{HPLC-FTIR interface}

A schematic diagram of the revised HPLC-FTIR thermospray interface assembly is shown in Fig. 1. Detailed descriptions of the interface have been given elsewhere. ${ }^{15-18}$ The column effluents were transferred to the thermospray interface assembly, which was surrounded by a heated nitrogen gas stream supplied by two channels at $51 \mathrm{~min}^{-1}$ from each channel, which continually flowed down to the thermospray capillary tubing $(125 \mu \mathrm{m}$ i.d. $\times 1.5 \mathrm{~mm}$ o.d.) and was used to enhance the solvent evaporation. The desolvated solutes were deposited as individual solute spots onto the surface of a moving stainlesssteel belt $(13 \mathrm{~mm}$ width $\times 0.025 \mathrm{~mm}$ thickness). As described previously, to minimize the problems experienced with solute deposition and chromatographic resolution, an extra heating plate $(8 \mathrm{~mm}$ thickness $\times 17 \mathrm{~mm}$ width $\times 100 \mathrm{~mm}$ length) was set just underneath the moving belt. A voltage regulator (KSC, Switching, Korea) was used to heat the plate at $110^{\circ} \mathrm{C}$. A variation of $\pm 3^{\circ} \mathrm{C}$ in the thermospray capillary temperature led to deposition problems ${ }^{14}$ and non-uniform deposition. ${ }^{15}$ The

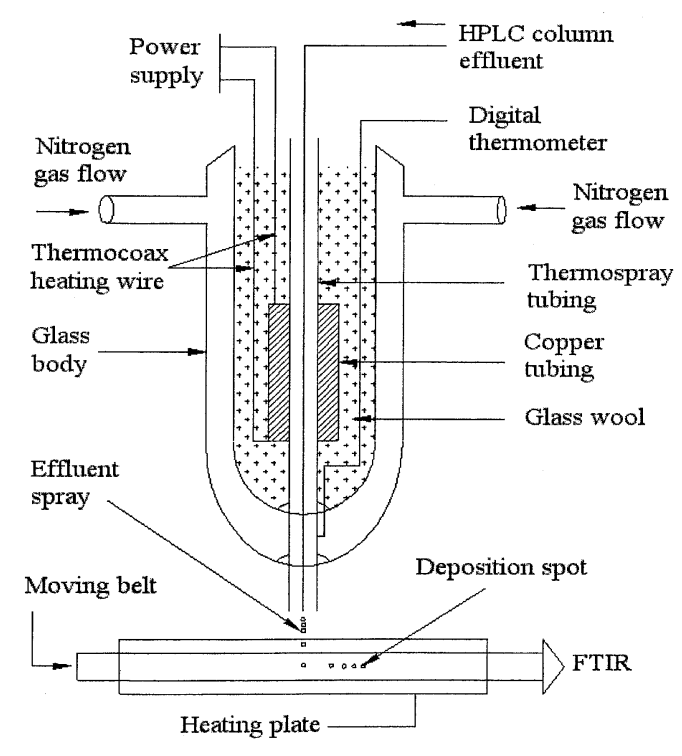

Fig. 1 Schematic diagram of the HPLC-FTIR with the modified thermospray interface assembly. Also see Refs. $14-18$.

extra heating plate underneath the moving belt was used to prevent non-uniform deposition and to enhance solvent evaporation. The addition of a heating plate and the second channel for nitrogen gas flow in the revised thermospray interface was the main difference from the previously used interface assembly. ${ }^{15}$ The moving belt continuously transferred the solutes into the FTIR where the IR spectra of deposited solutes were obtained by focusing the IR beam on the chromatographic spot. The background spectra were taken from a clean part of the belt surface immediately before the solute deposits of interest. A specially developed HPLC-FTIR chromatogram software was used to process these data and to construct an FTIR detection chromatogram by calculating the integrated IR absorbance across the selected wavenumber windows, as a function of time. The selected wavenumber windows represent a particular functional group of the compounds. The standard FTIR spectra were collected in the usual way using a $\mathrm{KBr}$ disc. The antioxidants (Irganox samples), methanol (HPLC grade), and acetonitrile (HPLC grade) were obtained from Ciba Geigy Ltd., UK and Merck, Germany, respectively. A known amount of sample was dissolved in a $50 \mathrm{ml}$ volumetric flask to give a concentration of $5 \mathrm{mg} \mathrm{ml}^{-1}$, this was then diluted to a working concentration of 1

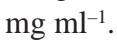

\section{Results and Discussion}

\section{Factors affecting HPLC-FTIR thermospray deposition}

Effluent desolvation, followed by deposition of solutes on belt surfaces is the most important factors amongst the parameters associated with HPLC-FTIR thermospray deposition. The size or area of the deposited spot directly influences the HPLC-FTIR performance, because the high sensitivity of FTIR detection can only be achieved if the spot size can be made as small as possible on the belt. However, this key issue depends on the thermospray and HPLC operating parameters. Such thermospray parameters as solvent evaporation, thermospray temperature, thermospray height (nozzle tip above belt), and heated gas flow rates also depend upon the composition and 
Table 1 Comparison of desolvation performance of the modified thermospray assembly for evaporation of different solvents and their mixtures at various flow rates

\begin{tabular}{|c|c|c|c|c|c|c|}
\hline \multirow{3}{*}{ Solvent } & \multirow{3}{*}{ Composition } & \multirow{3}{*}{$\begin{array}{l}\text { Flow rate/ } \\
\mathrm{ml} \mathrm{min}^{-1}\end{array}$} & \multicolumn{4}{|c|}{ Desolvation temperature and applied voltage to the thermospray capillary } \\
\hline & & & \multicolumn{2}{|c|}{ Gas flow rate $10 \mathrm{~L} \mathrm{~min}^{-1}$} & \multicolumn{2}{|c|}{ Gas flow rate $6 \mathrm{~L} \mathrm{~min}^{-1}$} \\
\hline & & & Applied voltage/V & Temperature $/{ }^{\circ} \mathrm{C}$ & Applied voltage/V & Temperature $/{ }^{\circ} \mathrm{C}$ \\
\hline Acetonitrile & 1. $100 \%$ & 0.5 & 10.0 & 147 & 13.0 & 154 \\
\hline \multirow[t]{3}{*}{$(\mathrm{AN})$} & 2. $100 \%$ & 1.0 & 15.3 & 167 & 18.8 & 175 \\
\hline & 3. $100 \%$ & 1.5 & 18.6 & 178 & 22.0 & 187 \\
\hline & 4. $100 \%$ & 2.0 & 21.2 & 186 & 26.5 & 199 \\
\hline Methanol & 1. $100 \%$ & 0.5 & 11.1 & 146 & 13.5 & 150 \\
\hline \multirow[t]{3}{*}{$(\mathrm{MeOH})$} & 2. $100 \%$ & 1.0 & 16.3 & 155 & 20.0 & 163 \\
\hline & 3. $100 \%$ & 1.5 & 19.7 & 168 & 24.0 & 174 \\
\hline & 4. $100 \%$ & 2.0 & 22.5 & 177 & 28.3 & 187 \\
\hline Water & 1. $100 \%$ & 0.5 & 21.8 & 189 & 26.7 & 197 \\
\hline$\left(\mathrm{H}_{2} \mathrm{O}\right)$ & 2. $100 \%$ & 1.0 & 33.9 & 209 & 39.0 & 232 \\
\hline \multirow[t]{2}{*}{ Mixture } & $\mathrm{AN}: \mathrm{H}_{2} \mathrm{O}(1: 1)$ & 1.0 & 26.0 & 190 & 30.0 & 200 \\
\hline & $\mathrm{MeOH}: \mathrm{H}_{2} \mathrm{O}(1: 1)$ & 1.0 & 27.9 & 193 & 32.3 & 206 \\
\hline
\end{tabular}

a. Extra heating plate with a temperature of $110^{\circ} \mathrm{C}$ was used underneath the deposition belt. b. Reported values were taken from Ref. 15 .

flow rates of the mobile phase. Thus the optimum thermospray conditions will be different for various solvent compositions and flow rates.

\section{Desolvation of eluents by modified thermospray}

Many studies have focused on a variety of the complications limiting the desolvation of water eluent and the deposition of solutes. ${ }^{4-18}$ A thermospray temperature of as high as $280^{\circ} \mathrm{C}$ was adequate to completely evaporate pure water at $0.5 \mathrm{ml} \mathrm{min}{ }^{-1}$, and the thermal degradation of glycine was reported. ${ }^{14}$ The use of a heated gas flow $\left(61 \mathrm{~min}^{-1}\right)$ significantly reduced the

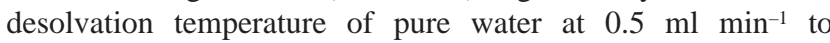
$197^{\circ} \mathrm{C} . .^{15}$ Although the temperature was lowered, a loss of resolution in FTIR detection ${ }^{15-17}$ and peak splitting ${ }^{18}$ were experienced. To improve the solute deposition and to achieve high sensitivity in FTIR detection, a heating plate and an additional gas flow channel were added to the modified thermospray system. Table 1 summarizes the overall performance of the modified thermospray interface for the desolvation of different single and mixed solvents. Irrespective of the solvents and the solvent flow rates, the use of a higher gas flow rate, such as $101 \mathrm{~min}^{-1}$, reduced the thermospray capillary voltage and lowered the solvent evaporation temperatures of acetonitrile, methanol, water, and their mixtures when compared to the reported values. ${ }^{15}$ For example, pure water $\left(0.5 \mathrm{ml} \mathrm{min}^{-1}\right)$ was desolvated at $189^{\circ} \mathrm{C}$, which is significantly lower than the reported values, $\left(280^{\circ} \mathrm{C}\right)^{14} /\left(197^{\circ} \mathrm{C}\right) .^{15}$ Even further lowering of the applied voltage and the desolvation temperature was achieved to evaporate water at $1 \mathrm{ml} \mathrm{min}{ }^{-1}$ compared to the literature values ${ }^{15}$, and also permitted the efficient deposition of solutes on the belt.

In order to investigate the effect of the heated gas flow rate and of the heating plate on the desolvation of eluents, an auxiliary heating tape was used to heat the nitrogen gas exactly in the same way as reported earlier. ${ }^{15}$ In this study, the auxiliary heating tape and heating plate temperatures were kept constant at $120^{\circ} \mathrm{C}$ and $110^{\circ} \mathrm{C}$, respectively. Figure 2 shows the effect of the heated nitrogen gas flow rates on the desolvation temperatures of different solvents at 0.5 to $2 \mathrm{ml} \mathrm{min}^{-1}$. An inverse relationship between the gas flow rates and the desolvation temperatures can be seen in this figure. The lowered desolvation temperature was achieved when higher gas flow rates were used. As stated earlier, the auxiliary-tape

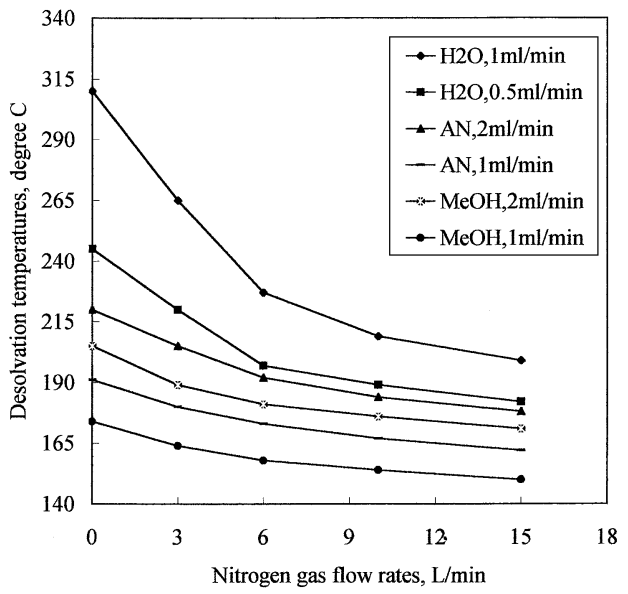

Fig. 2 Effect of varying the heated nitrogen gas flow rates on the desolvation temperatures of the reversed-phase HPLC eluents. Conditions: solvents, $100 \%$ acetonitrile (AN); $100 \%$ methanol $(\mathrm{MeOH}) ; 100 \%$ water; column, ODS (dimension, $250 \times 4.6 \mathrm{~mm}$ i.d.); auxiliary heating tape temperature $120^{\circ} \mathrm{C}$; thermospray height, 0.3 $\mathrm{cm}$; heating plate temperature $110^{\circ} \mathrm{C}$.

temperature was constant, so the nitrogen gas flow through the thermospray assembly lowered the desolvation temperatures of water, methanol and acetonitrile eluents. The heating plate (underneath the deposition belt) aided the evaporation.

\section{Deposition efficiency}

To measure the deposition efficiency, an Irganox 565 solution (20 $\mu \mathrm{l}$ of $1 \mathrm{mg} \mathrm{ml}^{-1}$ ) was injected into the HPLC-UV system and the solute was deposited as a spot on the belt under optimum conditions. A portion $(1.5 \mathrm{~cm})$ of the belt was cut by scissors by keeping the solute spot in the middle of the $1.5 \mathrm{~cm}$ portion. The cut portion of the belt was placed in a graduated tube containing $5 \mathrm{ml}$ of methanol. After shaking for a few minutes, the solute spot was re-dissolved in methanol, and then the belt was taken out from the tube. The volume of the solution was reduced to $200 \mu \mathrm{l}$ by an evaporative concentration method. Again, $20 \mu \mathrm{l}$ of the concentrated solution was injected into the HPLC instrument. An integrator gave the solute peak areas for 
Table 2 Reproducibility of the deposition spots for Irganox 565 sample deposited on the stainless-steel belt at different thermospray temperature

\begin{tabular}{ccc}
\hline $\begin{array}{c}\text { Thermospray } \\
\text { temperature } /{ }^{\circ} \mathrm{C}\end{array}$ & $\begin{array}{c}\text { Mean of IR absorbance } \\
\text { at } 2915 \mathrm{~cm}^{-1}\left( \pm \mathrm{SD}^{\mathrm{a}}\right)\end{array}$ & RSD, \% \\
\hline 145 & $0.1101 \pm 0.042$ & 38.2 \\
150 & $0.2130 \pm 0.029$ & 13.6 \\
153 & $0.4781 \pm 0.027$ & 5.6 \\
154 & $0.6988 \pm 0.016$ & 2.3 \\
155 & $0.7161 \pm 0.013$ & 1.8 \\
156 & $0.7049 \pm 0.018$ & 2.5 \\
158 & $0.6080 \pm 0.033$ & 5.4 \\
162 & $0.4614 \pm 0.036$ & 7.8 \\
166 & $0.2989 \pm 0.029$ & 9.7 \\
\hline
\end{tabular}

a. Standard deviation (SD) was determined from each of the five measurements.

the two measurements. The deposition efficiency was determined using the following equation:

$$
\text { deposition efficiency }=A_{\mathrm{rd}} \times 200 / 20 \times 100 / A_{\mathrm{fr}} \text {, }
$$

where, $A_{\mathrm{rd}}$ and $A_{\mathrm{fr}}$ represent the peak area of the re-dissolved and freshly prepared solution of Irganox 565, respectively. The deposition efficiency using the modified thermospray for an HPLC-FTIR analysis of the Irganox sample was found to be $69 \%$, which is approximately 7 -fold higher than the reported value $(10 \%){ }^{11-13}$ Hence, it was concluded that the modified thermospray could provide better results than the previously devised interface. ${ }^{15}$

\section{Effect of the thermospray temperature and thermospray height}

Any fluctuation of the thermospray temperature during interface operation influences the reproducibility of solute deposition on the moving belt. A variation of $\pm 3^{\circ} \mathrm{C}$ in the thermospray capillary temperature was reported to give poor reproducibility and non-uniform deposition. ${ }^{15-18}$ Irganox 565 was considered to be a test material to compare the effects of the thermospray temperature, the deposition reproducibility and the thermospray height for the deposition of solutes on the belt surface, because this material was the same as that used in Ref. 15. Also, the same chromatographic conditions were used to compare the performance of the modified thermospray with the previously assembled thermospray interface. Figure 3 shows the effect of the thermospray temperature on the magnitude of IR absorbance at $2915 \mathrm{~cm}^{-1}$. It can be observed that the maximum IR absorbance was obtained as 0.72 abs unit at a thermospray temperature of $155^{\circ} \mathrm{C}$, whereas the reported values were $0.61 \mathrm{abs}$ unit at $162^{\circ} \mathrm{C} .{ }^{15}$ Because the same conditions were used, this suggests that the modified thermospray offered better deposition and improved desolvation abilities. At temperatures lower than $154^{\circ} \mathrm{C}$, solvent vaporization was not complete. The heating plate temperature (underneath the deposition belt) was not adequate to evaporate the wet spray produced by the thermospray capillary, and solutes were deposited as wider spots over the surface of the belts, resulting in a reduction of the IR absorbance. At temperatures of 154 to $156^{\circ} \mathrm{C}$, the solvent was evaporated, so that the solute became a sticky or pasty material, suitable for concentrated deposition spots. Under such conditions, the area of the spot on the moving surface became smaller $(2-3 \mathrm{~mm}$ diameter $)$ and matched more closely the IR beam diameter (about $2 \mathrm{~mm}$ ) in the DRIFT accessory. Hence, an increase in the IR absorbance was obtained. At a temperature of $158^{\circ} \mathrm{C}$, the solvent was

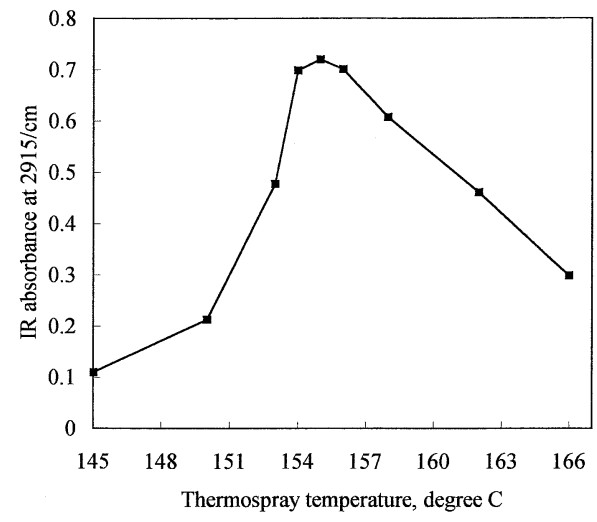

Fig. 3 Effect of varying the thermospray temperature on the magnitude of the IR absorbance at $2915 \mathrm{~cm}^{-1}$ for the deposition of Irganox 565. Conditions: solvents, $100 \%$ methanol; flow rate $0.5 \mathrm{ml}$ $\mathrm{min}^{-1}$; sample loop, $20 \mu \mathrm{l}$; column, ODS (dimension, $250 \times 4.6 \mathrm{~mm}$ i.d.); auxiliary heating tape temperature $120^{\circ} \mathrm{C}$; thermospray height, $0.3 \mathrm{~cm}$; heating plate temperature $110^{\circ} \mathrm{C}$; nitrogen gas flow rate, 101 $\mathrm{min}^{-1}$; belt speed, $0.35 \mathrm{~cm} \mathrm{~min}^{-1}$ for deposition and $0.13 \mathrm{~cm} \mathrm{~min}^{-1}$ for data acquisition; concentration of injected solution, $1 \mathrm{mg} \mathrm{ml}^{-1}$.

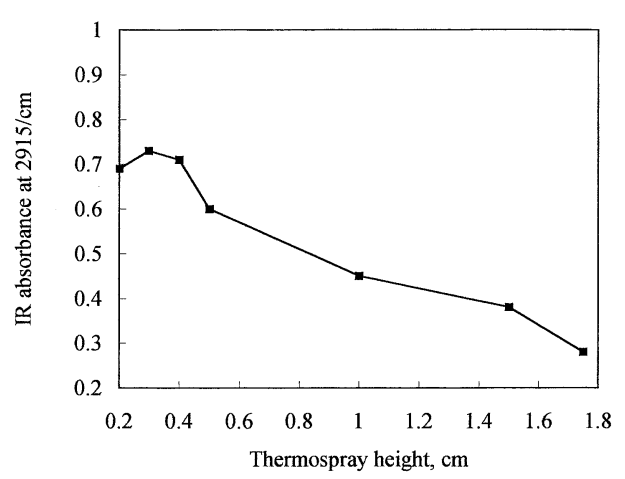

Fig. 4 Effect of varying the thermospray height on the magnitude of the IR absorbance at $2915 \mathrm{~cm}^{-1}$ for the deposition of Irganox 565 . Conditions: thermospray temperature, $155^{\circ} \mathrm{C}$ and other conditions are same as in Fig. 3.

almost dry and the area of the spots did not match with the IR beam area, resulting in a decrease in the IR absorbance. At a temperature above $158^{\circ} \mathrm{C}$, the solvent was totally evaporated and the solute was completely dried. The dried materials were bounced and spread during deposition on the belt, and consequently a non-uniform deposition was observed.

The reproducibility of the thermospray deposition was investigated for the deposition of solutes at various thermospray temperatures, and methanol was passed through the HPLCFTIR interface at a flow rate of $0.5 \mathrm{ml} \mathrm{min}{ }^{-1}$. Table 2 depicts the IR absorbance of Irganox 565 monitored at $2915 \mathrm{~cm}^{-1}$ at thermospray temperatures of 145 to $166^{\circ} \mathrm{C}$. The most reproducible and sensitive deposition occurred between thermospray temperature of 154 and $156^{\circ} \mathrm{C}$ with relative standard deviation (RSD) values of 1.8 to $2.5 \%$. It can also be seen that the IR absorbance values obtained at $155 \pm 1{ }^{\circ} \mathrm{C}$ are quite close to each other. Hence, it was concluded that a variation of $\pm 1^{\circ} \mathrm{C}$ could be effectively used for HPLC-FTIR thermospray analysis.

Figure 4 shows the variation in the magnitude of IR absorbance at $2915 \mathrm{~cm}^{-1}$ along with the thermospray height. It can be observed that the magnitude of the IR absorbance is 


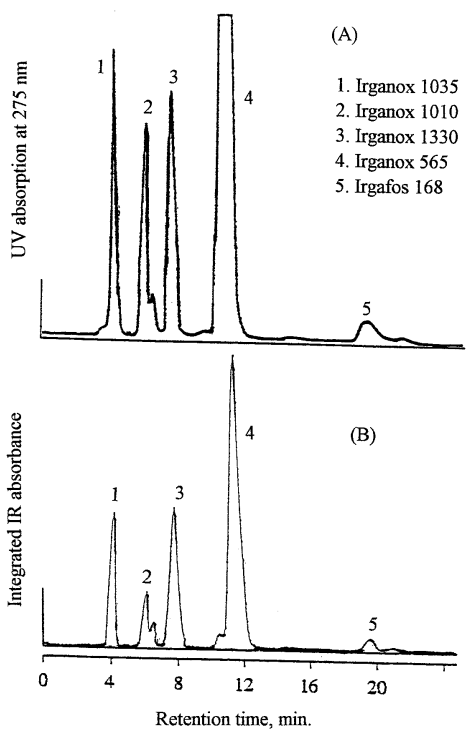

Fig. 5 HPLC chromatograms for (A) UV detection at $275 \mathrm{~nm}$ and (B) FTIR detection $\left(v\right.$ window $\left.=3100-2800 \mathrm{~cm}^{-1}\right)$ for the analysis of the phenolic antioxidants. The conditions are same as in Fig. 3 .

increased when the height of the thermospary is decreased. This is due to the fact that the area of the deposited solute spot on the moving belt increases with decreasing the thermospray height. During deposition experiments, when a thermospray height of $0.5 \mathrm{~cm}$ or above was used, the solutes did not deposit uniformly on the surface of the belt, resulting in poor solute deposition, and thus providing a weak IR absorbance. These facts also suggest that a thermospray height above the stainlesssteel belt of $0.3 \pm 0.1 \mathrm{~cm}$ is satisfactory.

\section{UV-FTIR detection and FTIR analysis}

Figure 5 shows HPLC chromatograms for (A) UV detection at $275 \mathrm{~nm}$ and (B) FTIR detection for a wavenumber window range of $3100-2800 \mathrm{~cm}^{-1}$ for the analysis of phenolic antioxidants. It was possible to "universally" detect all compounds by selecting the $\mathrm{C}-\mathrm{H}$ stretching vibration of hydrocarbon from 3100 to $2800 \mathrm{~cm}^{-1}$, because all of the antioxidants contained both aromatic and aliphatic features (Fig. 6). The FTIR chromatogram showed excellent matching of the chromatographic features and the retention behavior of the isolated peaks to that of the UV detection. The loss in resolution and peak splitting were minimized by the heating plate underneath the deposition belt. This can be explained as follows: before a minor spreading of the residue solvent (which sticks to the deposited materials) on the belt surface, the heating plate evaporated the residue solvents quickly and the deposited solutes could not spread on the belt surface; as a result uniform spots were obtained. Minimization of the resolution loss was achieved when the uniform spots were scanned by FTIR (see Fig. 5(B)). This is one of the major achievements of the modified HPLC-FTIR thermospray. A slight increase in the elution times in the FTIR plot can be seen as the eluate passed first through the UV detector before flowing through the connection tubing to the thermospray. Table 3 summarizes the resolution (Rs) data obtained from the UV and FTIR detection chromatograms (Figs. 5(A) and (B)). This suggests that the Rs values obtained from each peak compare well with each other. Hence, it was decided that the modified thermospray performed better than the previously used interface. ${ }^{14-18}$

To examine the thermal suitability of the analyzed samples,
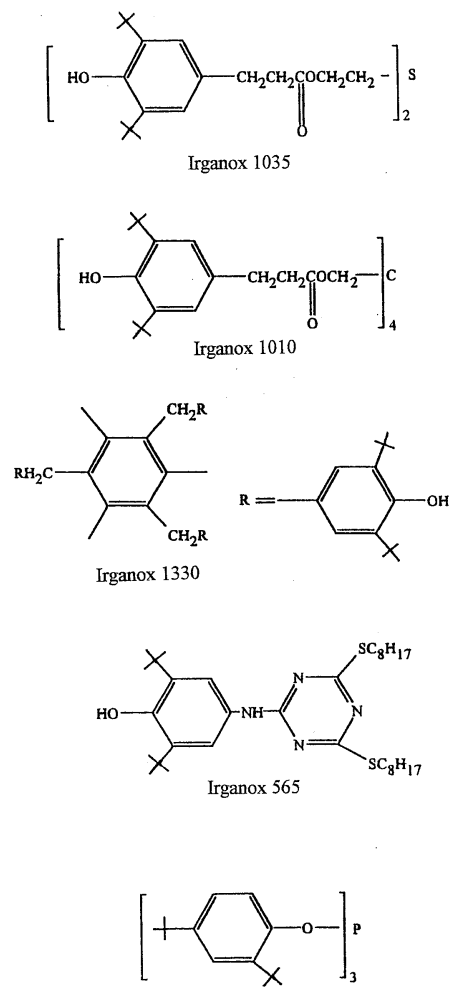

Irgafos 168

Fig. 6 Molecular structure of phenolic antioxidants analyzed by an HPLC-FTIR modified thermospray interface.

identification of the Irganox 565 and Irgafos 168 was investigated. Figure 7 compares the spectra obtained from the HPLC-FTIR interface and the standard FTIR. The interfacederived spectra in Figs. 7(A) and (B), corresponding to Irganox 565 and Irgafos 168, were taken from peaks " 4 " and " 5 " at retention times of 10.83 and $18.84 \mathrm{~min}$ in the FTIR chromatogram (Fig. 5(B)). These show excellent agreements of the absorption features between each pair of spectra throughout the whole absorption spectral range from 4000 to $600 \mathrm{~cm}^{-1}$. This suggests that no thermal degradation of these antioxidants occurred during thermospray deposition. The IR spectra of other deposition spots of the antioxidants were compared to those of the standard FTIR spectra, and showed excellent similarities in the spectral features. These are not shown.

In conclusion, a thermospray interface was revised by introducing a gas flow channel and a heating plate underneath the deposition belt to extend the applicability of HPLC-FTIR in pharmaceutical and biomedical areas. This system performs better than the previously devised interface. Increased heated nitrogen flow rates improved the desolvation of methanol, acetonitrile and water and reduced the voltage requirement in the thermospray capillary tubing. Desolvated solutes were deposited as individual spots on a moving belt surface. An improved deposition efficiency by a factor of seven and the peak resolution in the FTIR chromatogram were achieved. Pure water at $0.5 \mathrm{ml} \mathrm{min}{ }^{-1}$ was desolvated at $189^{\circ} \mathrm{C}$, which is much lower than the reported value of $280^{\circ} \mathrm{C}$. Even $100 \%$ water at a flow rate of $1 \mathrm{ml} \mathrm{min}{ }^{-1}$ was evaporated at $209^{\circ} \mathrm{C}$ with smooth operation of the HPLC-FTIR. The thermospray temperature and the height above the belt influenced the deposition of solutes and the IR absorption bands. A variation of $\pm 1^{\circ} \mathrm{C}$ from the optimum thermospray temperature $\left(155^{\circ} \mathrm{C}\right)$ could be used 
Table 3 Comparison of the chromatographic resolution between the peaks of the UV and FTIR detection chromatograms separated by HPLC

\begin{tabular}{ccc}
\hline $\begin{array}{c}\text { Peak in the UV } \\
\text { and FTIR detection } \\
\text { chromatogram } \\
\text { (Figs. 5A and B) }\end{array}$ & $\begin{array}{c}\text { Chromatographic resolution } \\
\text { between the peaks of the HPLC } \\
\text { chromatogram }\end{array}$ \\
\cline { 2 - 3 } Peak 2 & UV detection & FTIR detection \\
Peak 3 & 3.09 & 3.09 \\
Peak 4 & 2.77 & 2.31 \\
Peak 5 & 2.99 & 3.1 \\
\hline
\end{tabular}

for the sensitive and reproducible deposition of Irganox 565 at $0.5 \mathrm{ml} \mathrm{min}{ }^{-1}$ with RSD values of 1.8 to $2.5 \%$. The IR spectra of deposited constituents showed excellent agreement of spectral features with those of the standard FTIR spectra without any evidence of thermal degradation.

\section{Acknowledgements}

The author (M. A. M.) would like to thank Dr. G. Wayne Sovocool, Research Scientist, Environmental Sciences Division, National Exposure Research Laboratory, US Environmental Protection Agency, Las Vegas, Nevada for his helpful cooperation while correcting the manuscript/proof.

\section{References}

1. C. C. Johnson and L. T. Taylor, Anal. Chem., 1984, 56, 2642.

2. P. G. Amateis and L. T. Taylor, Chromatographia, 1984, $18,175$.

3. K. L. Kizer, A. W. Mantz, and L. C. Bonar, Am. Lab., 1979, 7, 85.

4. D. J. Wood, Spectrosc. Int., 1990, 2, 36.

5. C. Fujimoto, T. Oosuka, and K. Jinno, Anal. Chim. Acta, 1985, 159, 178.

6. J. J. Gagel and K. Biemann, Anal. Chem., 1988, 60, 2184 and 1987, 59, 1266.

7. T. C. Shunk, T. Balke, and P. Cheung, J. Chromatogr., 1994, 661, 227.

8. J. L. Dwyer, A. E. Chapman, and X. Liu, LC-GC Int., 1995, 8, 704.

9. R. M. Robertson, J. A. de Haseth, and R. F. Browner,
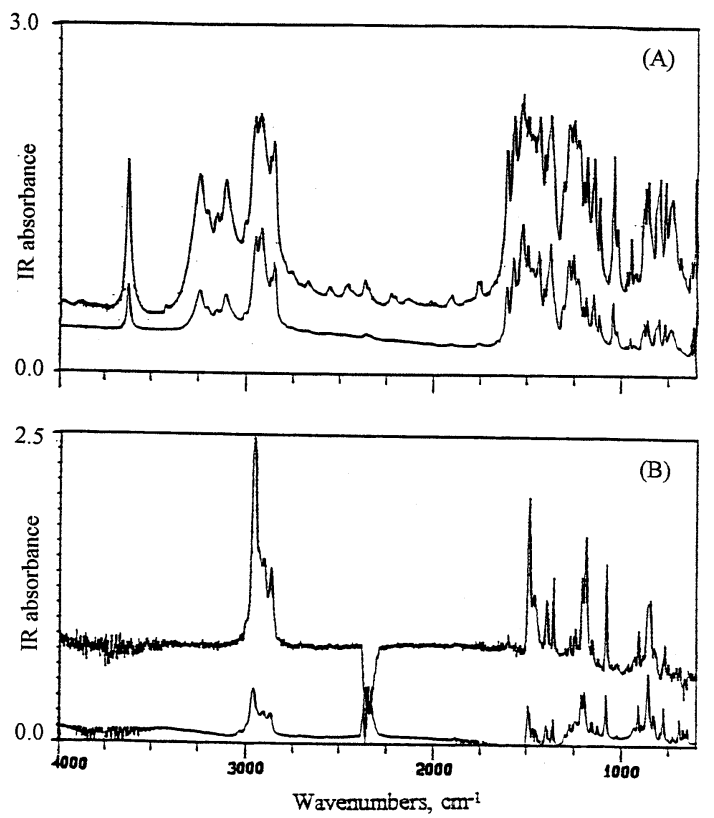

Fig. 7 Overlay of HPLC-FTIR interface and standard FTIR spectra of the Irganox samples. For (A) Irganox 565; interface spectrum (lower: scale expansion, $\times 3$ ) and standard FTIR spectrum (upper): and (B) Irgafos 168; interface spectrum (upper: scale expansion, $\times 6$ ) and standard FTIR spectrum (lower). The interface spectra were taken from peaks " 4 " and " 5 " at retention times of 10.83 and 18.84 min from Fig. 6(B). The conditions are same as in Fig. 5.

Mikrochim. Acta, 1988, 11, 199.

10. R. M. Robertson, J. A. de Haseth, and R. F. Browner, Appl. Spectrosc., 1990, 44, 8.

11. K. L. Norton, A. J. Lange, and P. R. Griffiths, J. High Res. Chromatogr., 1991, 14, 225.

12. A. J. Lange and P. R. Griffiths, J. Chromatogr. Sci., 1992, 30, 93.

13. J. A. J. Jansen, Fresenius J. Anal. Chem., 1990, 337, 398.

14. A. M. Robertson, L. Wylie, D. Littlejohn, and C. J. Dowle, Anal. Proc., 1991, 28, 8.

15. M. A. Mottaleb, Anal. Sci., 1999, 15, 57 and more references therein.

16. M. A. Mottaleb, Mikrochim. Acta, 1999, 132, 31; Anal. Sci., 1999, 15, 1137.

17. J. C. Jones, D. Littlejohn, and P. R. Griffiths, Appl. Spectrosc., 1999, 53, 792.

18. M. A. Mottaleb and D. Littlejohn, Anal. Sci., 2001, 17, 429. 